\title{
Aberta, Irreverente e do Bem: Uma Investigação dos Discursos Slow Fashion a partir do Caso Dobra
}

O slow fashion é um movimento onde busca-se a desaceleração da moda no sentido de repensar práticas e não diminuir a velocidade da produção em si, criando um novo paradigma de consumo, que prioriza a sustentabilidade, a durabilidade e a ética. Este trabalho busca investigar os discursos e significados em torno do conceito slow fashion por meio de uma pesquisa qualitativa Netnográfica realizada no perfil oficial da marca Dobra no Instagram. O trabalho apresenta três temas relevantes na constituição do discurso slow fashion: 1 ) Produção e Ética, 2) Design, e 3) Co-criação. A partir da dimensão co-criação o trabalho enriquece o framework do processo slow fashion, evidenciando a relevância dessa dinâmica e a natureza circular e iterativa, entre consumidores e marcas - em múltiplas direções - na constituição da lógica lenta de consumo.

Palavras-chave: Slow Fashion; Comportamento do consumidor; Co-criação; Dobra.

\section{Open, Irreverent and Sustainable: An Investigation of Slow Fashion Discourses in the Dobra Case}

Slow fashion is a movement that seeks to slow down fashion in order to rethink practices and not slow down the production speed itself, creating a new consumption paradigm, which prioritizes sustainability, durability and ethics. This work seeks to investigate the speeches and meanings around the slow fashion concept. through a qualitative Netnographic survey conducted on the official profile of the brand Dobra on Instagram. The work presents three relevant themes in the constitution of the Slow Fashion discourse: 1) Production and Ethics, 2) Design, and 3) Co-creation. From the co-creation dimension, the work enriches the slow fashion process framework, showing the relevance of this dynamic and the circular and iterative nature, between consumers and brands - in multiple directions - in the constitution of the slow consumption logic.

Keywords: Slow Fashion; Consumer Behaviour; Co-creation; Dobra.

\section{Introdução}

O slow fashion é um movimento onde busca-se a desaceleração da moda no sentido de repensar práticas e não diminuir a velocidade da produção em si, criando um novo paradigma de consumo, que prioriza a sustentabilidade, a durabilidade e a ética (FLETCHER, 2010). Esse movimento busca também a relação emocional do consumidor com cada peça; criando um sentimento de apreciação no consumo. No Brasil, essa tendência se manifesta no interesse de grandes marcas que começam a se voltar para um modelo de produção mais

\footnotetext{
${ }^{1}$ Graduando em Defesa e Gestão Estratégica Internacional, Universidade Federal do Rio de Janeiro (UFRJ). Bolsista de Iniciação Científica FAPERJ - COPPEAD. Endereço: Rua Pascoal Lemme, 355, Rio de Janeiro - RJ - CEP: 21941-918. E-mail: lucas.mulim@coppead.ufrj.br. ORCID: https://orcid.org/0000-0002-8813-7110.

2 Doutora em Administração pela Pontifícia Universidade Católica - Puc - Rio. Professora do Instituto COPPEAD de PósGraduação em Administração. Endereço: Rua Pascoal Lemme, 355, Rio de Janeiro - RJ - CEP: 21941-918. E-mail: maribels@coppead.ufrj.br. ORCID: https://orcid.org/0000-0001-9736-5273.
} 
sustentável e responsável e também no aumento da procura por itens de segunda mão - os brechós (ÉPOCA NEGÓCIOS, 2019).

Neste modelo de se produzir e consumir moda, um dos desafios está na comunicação e relacionamento das marcas e consumidores, viabilizando a transformação de valores, lógicas e hábitos de consumo, calcados na velocidade do consumo acelerado de substituição de peças para a redução do ciclo de compra e descarte. Conforme observado por Pookulangara e Shephard (2013), a comunicação abre as portas para o processo de transparência, que por sua vez atrai e educa os consumidores, constituindo um aspecto chave da transformação na lógica de consumo. A comunicação também é fundamental para que a percepção de valor do produto seja ampliada. Esta viabiliza a prática de preços acima da média do mercado para os produtos slow fashion, criando margens que viabilizam negócios organizados a partir da desaceleração (POOKULANGARA; SHEPHARD, 2013).

A presente pesquisa se propõe a investigar as interações de comunicação e de relacionamento de uma marca brasileira de slow fashion. O objetivo deste trabalho é analisar as informações oferecidas pela empresa aos seus consumidores e como estes consumidores reagem, elaboram e co-criam tais informações. Nesse sentido, busca-se inventariar os discursos e significados em torno do conceito slow fashion.

Para isso, a pesquisa realiza uma netnografia, jogando luz para a interação dos consumidores com a marca Dobra, no contexto do Instagram. Fundada em $2016 \mathrm{com}$ a ideia de vender carteiras de Tyvek, material com textura e a aparência similar ao papel, a Dobra comercializa camisas com bolsos intercambiáveis e tênis, ambos feitos do mesmo material. A empresa ganhou destaque por propor uma lógica de negócios que pretende ser socialmente e ambientalmente limpa, uma postura sintetizada no seu slogan atual: "aberta, irreverente e do bem". Destaca-se também na marca, a constante busca de se posicionar para além de uma loja; buscando trazer para os seus consumidores, além dos produtos - uma experiência de consumo que é composta principalmente pelo propósito de existência da marca e pela metodologia de comunicação aplicada por eles em seus meios de comunicação. Apesar de ser uma nova e pequena empresa, a Dobra acumula nas redes sociais cerca de 184 mil seguidores.

\section{Revisão de Literatura}

Mais do que um questionamento do consumo como fonte de satisfação e bem-estar, o movimento do consumo lento busca ressignificar os prazeres do consumo (HUMPHERY, 2013). A lógica slow fashion se manifesta em categorias diversas como alimentação (SASSATELLI; DAVOLIO, 2010), turismo (CONWAY; TIMMS, 2010; OH; ASSAF; BALOGLU, 2014; HUSEMANN; ECKHARDT, 2018), e em diversas práticas da vida social, como o trabalho, a socialidade e as formas de viver em família (PARKINS; CRAIG, 2011). Osbaldiston (2013) nos lembra que o fastio gerado pela abundância de ofertas e de consumos instantâneos leva os indivíduos a explorarem abordagens alternativas de se viver.

Como nos lembram Miranda \& Monçores (2013), o "espírito do tempo" é essencial para a moda, por incorporar visões de mundo correntes, orientações e comportamentos das esferas política, cultural, intelectual, ética e espiritual predominante numa determinada época. No contexto da moda, a busca por desaceleração surge na contramão do movimento onde a grande indústria têxtil pisa no acelerador, ditando tendências, aumentando a 
periodicidade de coleções, encurtando lead time e, assim, criando uma oferta e demanda acelerada (OZDAMAR; ATIK, 2014).

A preocupação global com as questões ambientais coloca em julgamento essa lógica fast fashion, calcada nas roupas de baixo preço e nos ciclos de compra e descarte frequentes e acelerados (WATSON; YAN, 2013). A preocupação com o esgotamento de recursos naturais e também a quantidade de resíduo gerado - da linha de produção até o pós-consumo. (OZDAMAR; ATIK, 2015) fez emergir o impulso de desacelerar o consumo - como já é visível em alguns mercados (SCHOR, 2013). A desaceleração do consumo na moda, traz como base a busca por sustentabilidade e responsabilidade social - onde busca-se ressignificar o consumo de vestuário, resgatando o prazer e a experiência e assim criando um elo afetivo com essas peças (FLETCHER, 2010).

Em uma tentativa de compreender e trazer definições concretas acerca do slow fashion, Pookulangara e Shephard (2013) trazem uma perspectiva voltada ao entendimento do consumidor; agregando no conceito inicial trazido por Fletcher (2010), que o slow fashion não se trata de outro termo para moda ética ou então uma antítese ao fast fashion, mas sim um processo que parte da indústria ao consumidor, incorporando decisões conscientes em todos os níveis desta cadeia - que engloba design, produção e consumo (POOKULANGARA; SHEPHARD, 2013). Jung e Jin (2014) trazem uma outra abordagem ao tema, onde o slow fashion seria uma combinação entre produção e consumo lento; onde abriga-se valorização da mão de obra dos trabalhadores envolvidos na produção, produções de pequena escala, produtos com ciclos de vida mais longos e funcionais; além da valorização de pequenos negócios locais na cadeia produtiva.

\section{A empresa Dobra}

A Dobra foi fundada em 2016 por Eduardo Hommerding, Augusto Massena e Guilherme Massena no interior do Rio Grande do Sul - com a ideia de vender produtos sustentáveis e resistentes, com produção local e totalmente sob demanda - feitos de tyvek, uma fibra plástica com textura de papel. Hoje, com cerca de vinte e dois funcionários e faturamento estimado de 2,5 milhões por ano (VITORIO, 2019); a empresa já ampliou sua gama de produtos e além das tradicionais carteiras vendidas inicialmente, comercializam também calçados, camisas e bolsas. A marca aplica uma postura aberta e transparente; disponibilizando seus moldes e até mesmo uma página online ensinando a montar uma empresa igual a eles; dando dicas até mesmo de cola para usar na confeç̧ão das carteiras.

Uma das características mais marcantes da empresa é o seu modelo de gestão horizontal, onde não há hierarquia de cargos, todos possuem o mesmo salário e também participação nos lucros da empresa. Além da gestão, a Dobra se destaca também em ações sociais e sustentáveis. No eixo social, a marca possui diversos programas de reversão de porcentagem de venda para projetos sociais - como a reforma do pátio de uma escola municipal local, realizada no início de 2019. Na face sustentável, destaca-se o seu programa de reciclagem onde os consumidores podem enviar de volta para a marca carteiras e bolsas para serem reciclados - assim ganhando um desconto na próxima compra.

Outro destaque na trajetória da empresa é o modelo de campanha de Black Friday, onde ao invés de oferecer descontos nos produtos, a marca dá um produto de graça ou um grande desconto para os consumidores que realizarem qualquer doação para projetos sociais. 
Em 2017 foram arrecadados R\$ 20 mil; em 2018, R\$ 50 mil e em 2019, R\$ 62 mil. Em março de 2019 a empresa ganhou o reconhecimento como uma das dez startups mais conscientes, pelo movimento Capitalismo Consciente; que agrega empresas que visam impacto socioambiental positivo - presidido no Brasil pelo CEO do Grupo Reserva - Rony Meisler.

\section{Método}

Tendo por objetivo inventariar os discursos e significados em torno do conceito slow fashion no contexto brasileiro, a presente pesquisa investiga o caso Dobra, mais especificamente as interações de comunicação e relacionamento que acontecem nas mídias sociais. Para isso, o método utilizado foi o de netnografia (KOZINETS, 2015), que transpõe para o ambiente da internet os procedimentos etnográficos, como a imersão de natureza qualitativa por um período mais longo no ambiente e grupo a ser investigado. No contexto digital, a presente pesquisa se focará nas interações em torno do perfil oficial da marca no Instagram, a @querodobra. As postagens foram observadas do período de abril a agosto de 2019 e foram avaliados nas postagens as fotos, textos e comentários, que constituem as trocas de informação e os discursos em torno da marca. O Instagram foi escolhido como a plataforma a ser analisada não apenas por sua popularidade de maneira geral, mas por sua relevância no contexto da indústria da moda. Para entender mais profundamente o perfil da empresa, foram coletados dados secundários disponibilizados no site da marca. Esse acervo de textos inclui manuais e conteúdos que explicam como montar e gerenciar uma empresa como a Dobra. O primeiro autor assistiu ainda palestra de um dos sócios da marca, bem como realizou algumas interações com os funcionários da Dobra, através do perfil no Instagram.

No total, foram coletadas e analisadas 270 postagens no perfil oficial da marca. A partir desse corpus, foram criadas categorias de temas mais abordados nessa plataforma. A análise de dados foi feita de acordo com as orientações de Kozinets (2015), baseada na codificação dos posts coletados, atribuindo rótulos aos textos, imagens de cada postagem. $\mathrm{O}$ trabalho de codificação seguiu uma abordagem hermenêutica (THOMPSON, 1997), assim, em cada post buscava preservar o contexto original onde ocorreu a interação da marca com os consumidores. Tal processo de categorização teve uma natureza interativa, conciliando aspectos que emergiam dos próprios dados e conceitos oferecidos pelos estudos sobre slow fashion. Numa etapa inicial as codificações organizaram o material em torno de 17 temas: arte; características (de produto); feedback; colaboração; customização; emoções; relações familiares; experiência; gestão; igualdade de gênero; material; produção; propósito; relações de trabalho; responsabilidade social; identidade de público e por fim, sustentabilidade. Esses códigos iniciais permitiram realizar o trabalho transversal de comparar e contrastar os diferentes posts, fazendo emergir temas recorrentes presentes na comunicação da Dobra e seu público. Assim, num segundo momento, os códigos foram interpretados, identificando e comparando as simbologias presentes no discurso da marca, gerando a análise que será apresentada a seguir.

\section{Análise}

A análise das postagens no Instagram da marca Dobra sugerem três grandes grupos de temas recorrentes na comunicação da marca com seus consumidores: 1) aspectos relacionados à produção e ética; 2) o design em si dos produtos e 3) a relevância da co-criação 
em parceria com os consumidores para a marca. O modelo abaixo organiza esses três grandes temas e seus subtemas, evidenciando ainda as suas interseções.

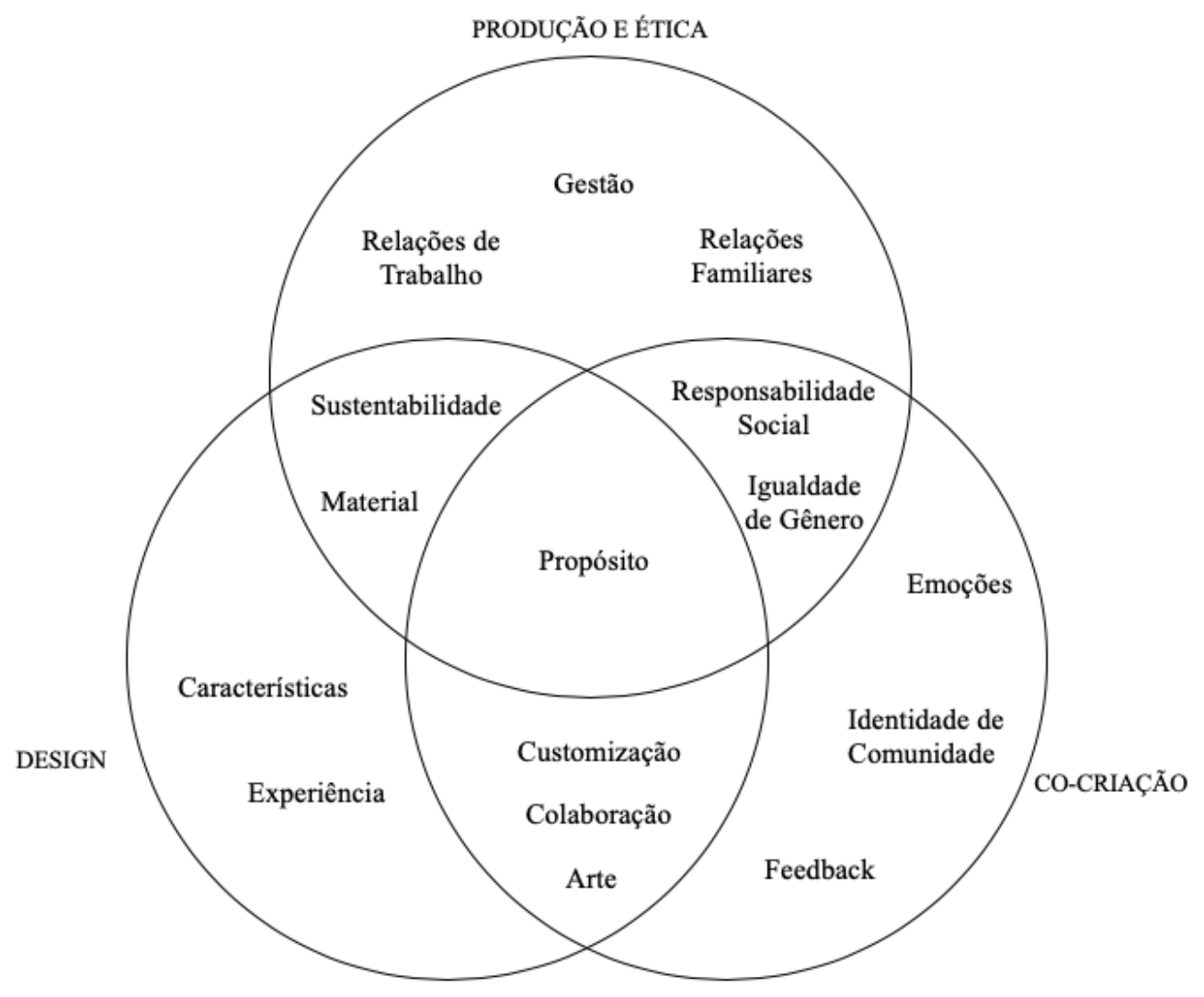

Figura 1. Esferas de Apreciação

Fonte: Elaborado pelos Autores

A seguir cada um dos temas será apresentado mais detalhadamente.

\subsection{Produção e ética}

A esfera da produção e ética abriga as questões que possuem maior peso na construção de transparência da marca - além disso, constitui o lado do Slow fashion que atua com responsabilidade social e sustentabilidade. É a esfera de apreciação que busca trazer do consumidor uma empatia com a marca, no sentido de construir uma imagem positiva com base nos ideais slow - e assim aproximar a Dobra dos consumidores engajados com sustentabilidade e responsabilidade social.

A postagem abaixo (Figura 2) se refere a uma campanha realizada no mês de abril de 2019, que é a semana do Fashion Revolution, quando ocorre um grande evento em diversos países para reunir marcas da indústria da moda e discutir sobre desenvolvimento sustentável e responsabilidade social. Nesse evento, participam principalmente marcas de Slow fashion e aquelas que tentam se aproximar deste modelo. 

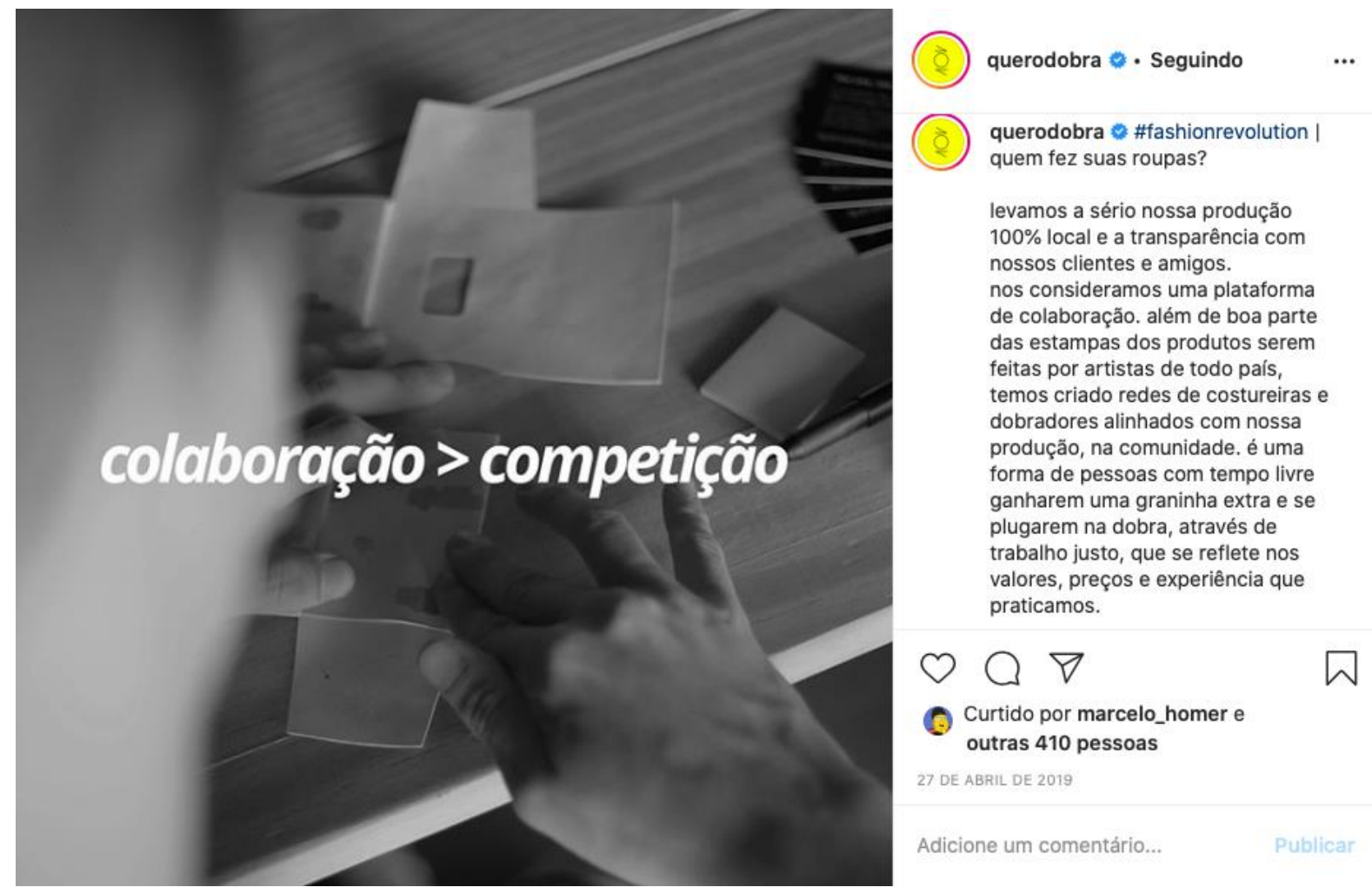

Figura 2. Campanha realizada pela marca para Semana Fashion Revolution.

Fonte: Instagram @Querodobra

No texto acima é possível observar o intuito de levar o consumidor a refletir sobre a origem dos produtos que utiliza, a partir da pergunta "Quem faz suas roupas"? Essa pergunta amplia a esfera de consumo, para além do momento da compra, incentivando o consumidor a pensar sobre o processo produtivo e o caminho que esta percorreu até chegar ao seu alcance. Mais do que fazer o consumidor refletir, a Dobra insere um discurso que pretende educar o consumidor para superar a lógica usual baseada no menor custo ou a menor preço, a partir dos processos de competição do mercado. Tal postura do âmbito ético é sintetizada pela ideia de que a colaboração deve ser maior do que a competição, como sugerido pela imagem que acompanha o texto. No comentário, a Dobra insere assim um novo item no processo decisório de compra, demonstrando o valor dos produtores locais, dos meios de produção da marca, e da transparência. Tal postura se reflete no texto que destaca a colaboração com artistas nacionais e redes de costureiras para ilustrar a ideia de que o que rege a construção de transparência da marca não é uma disputa de mercado e uma busca incessante por lucro, mas sim uma rede de colaboração onde todos os envolvidos no processo terão ganhos positivos. O post parece valoriza partes produtoras da moda que costumam ser alheias no processo de fast fashion, sendo invisíveis ou colocadas meramente como ferramentas de trabalho;

No post a seguir (figura 3), uma das costureiras da empresa ganha visibilidade, nome e voz. Nélia conta que "ama fazer parte dessa LOUCURA". Estes e os depoimentos de outras costureiras estão no blog da marca, fazendo com que o consumidor tenha contato com o 
processo de produção. Tal proximidade é viabilizada ainda por manuais disponíveis no site da marca, onde é possível aprender a fazer carteiras, como as vendidas pela Dobra.
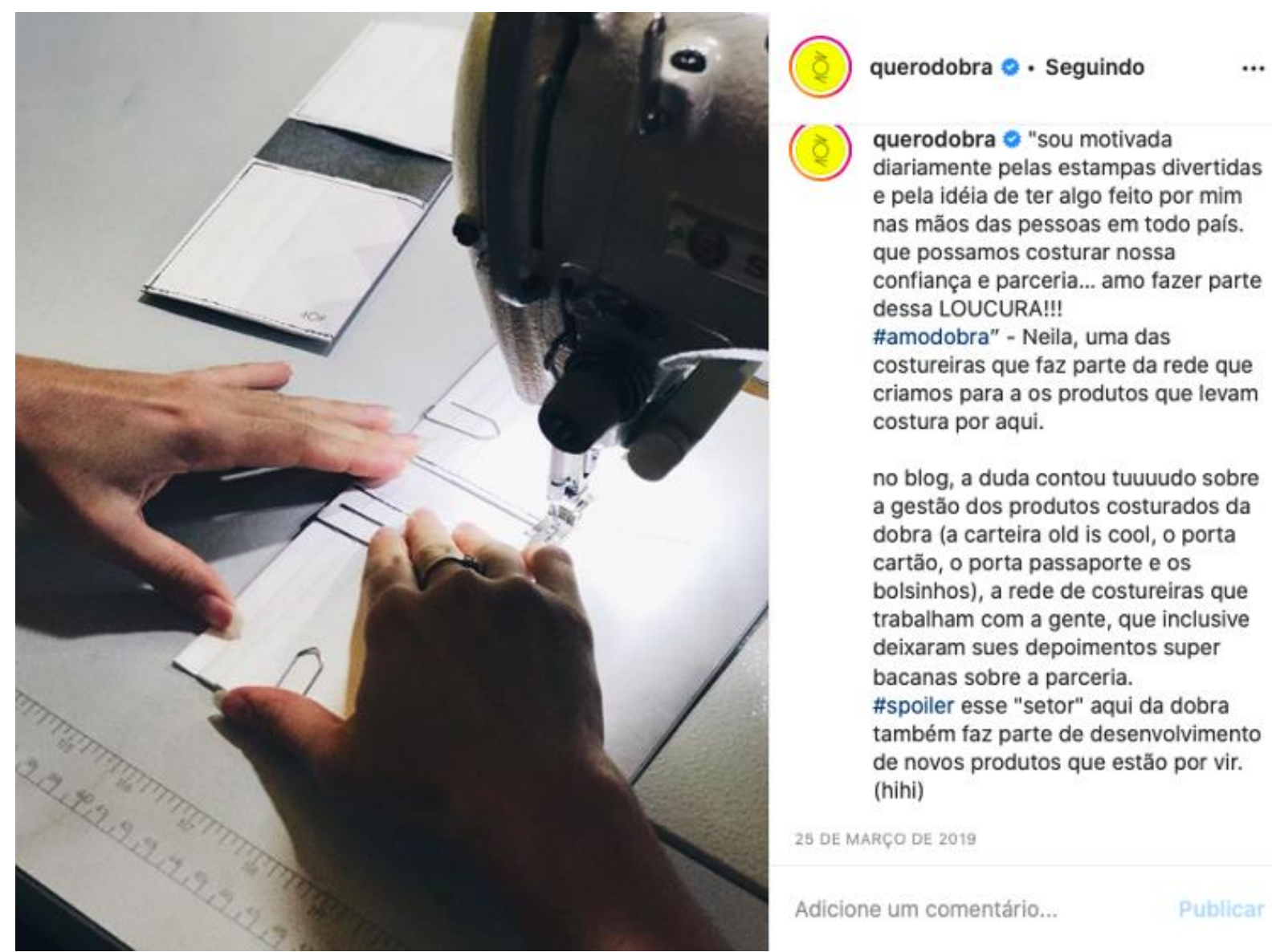

no blog, a duda contou tuuuudo sobre a gestăo dos produtos costurados da dobra (a carteira old is cool, o porta cartão, o porta passaporte e os bolsinhos), a rede de costureiras que trabalham com a gente, que inclusive deixaram sues depoimentos super bacanas sobre a parceria. \#spoiler esse "setor" aqui da dobra também faz parte de desenvolvimento de novos produtos que estăo por vir. (hihi)

25 DE MARÇO DE 2019

Adicione um comentário... Publicar

Figura 3. Depoimento de uma das costureiras colaboradoras da marca

Fonte: Instagram @Querodobra

A atitude ética da marca é reforçada em diversos posts que apresentam a narrativa de que a Dobra não existe só para vender produtos, mas sim realizar o seu propósito como um negócio que integra a sociedade; 

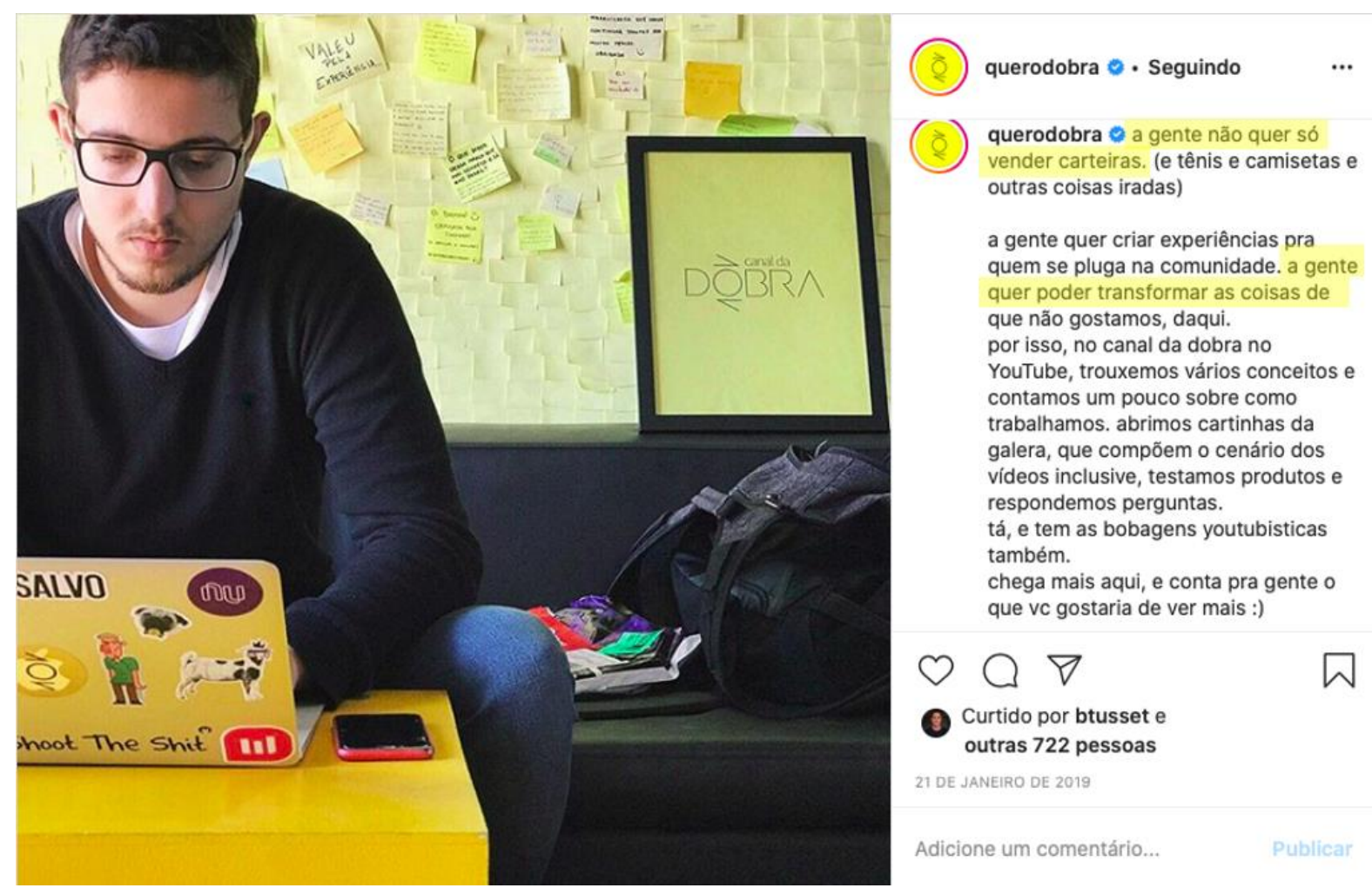

Figura 4.

Fonte: Instagram @Querodobra

A postagem acima parece se alinhar à lógica de capitalismo consciente (SISODIA; MACKEY, 2014). Segundo os autores, tal lógica pensa a realidade do negócio a partir do lucro, mas de seu propósito maior, refletindo sobre os impactos sobre o mundo e de suas relações com os diversos públicos e stakeholders.

\subsection{Design}

A esfera do design tem pontos de conexão com as narrativas sobre produção e ética, especialmente a partir da divulgação dos aspectos relacionados aos materiais e à preocupação com os aspectos de sustentabilidade da empresa e do meio ambiente. A empresa constrói um discurso que valoriza o consumidor apreciador. Este amplia seu olhar para além do aspecto estético do consumo, contemplando também os aspectos éticos. Como sugere o post abaixo, o consumidor tem muitos motivos para apreciar o produto por sua natureza que inclui o material, os meios de produção, seus impactos reduzidos na geração de resíduos e a diminuição de desperdícios. A dimensão de apreciação do design também constrói o aspecto colaborativo - por meio das estampas enviadas por artistas e da sustentabilidade - onde a empresa abre as portas para falar do material empregado e outras soluções ecológicas vindas do design (Figura 5). Como exemplo destacamos o copo eco que serve como embalagem para a bolsa e também para as camisas vendidas (Figura 6). A esfera do design possui um importante papel pois é a principal porta de co-criação com os consumidores, visto a facilidade de consumidores sugerirem novos produtos e melhorias nos já existentes. Além de ser uma 
das principais bases do slow fashion; juntando a sustentabilidade com a longevidade do uso do produto; evitando a obsolescência psicológica (FLETCHER, 2012) - onde um produto se torna defasado por meio de uma construção social - e não por fisicamente no seu uso, se tornar obsoleto.
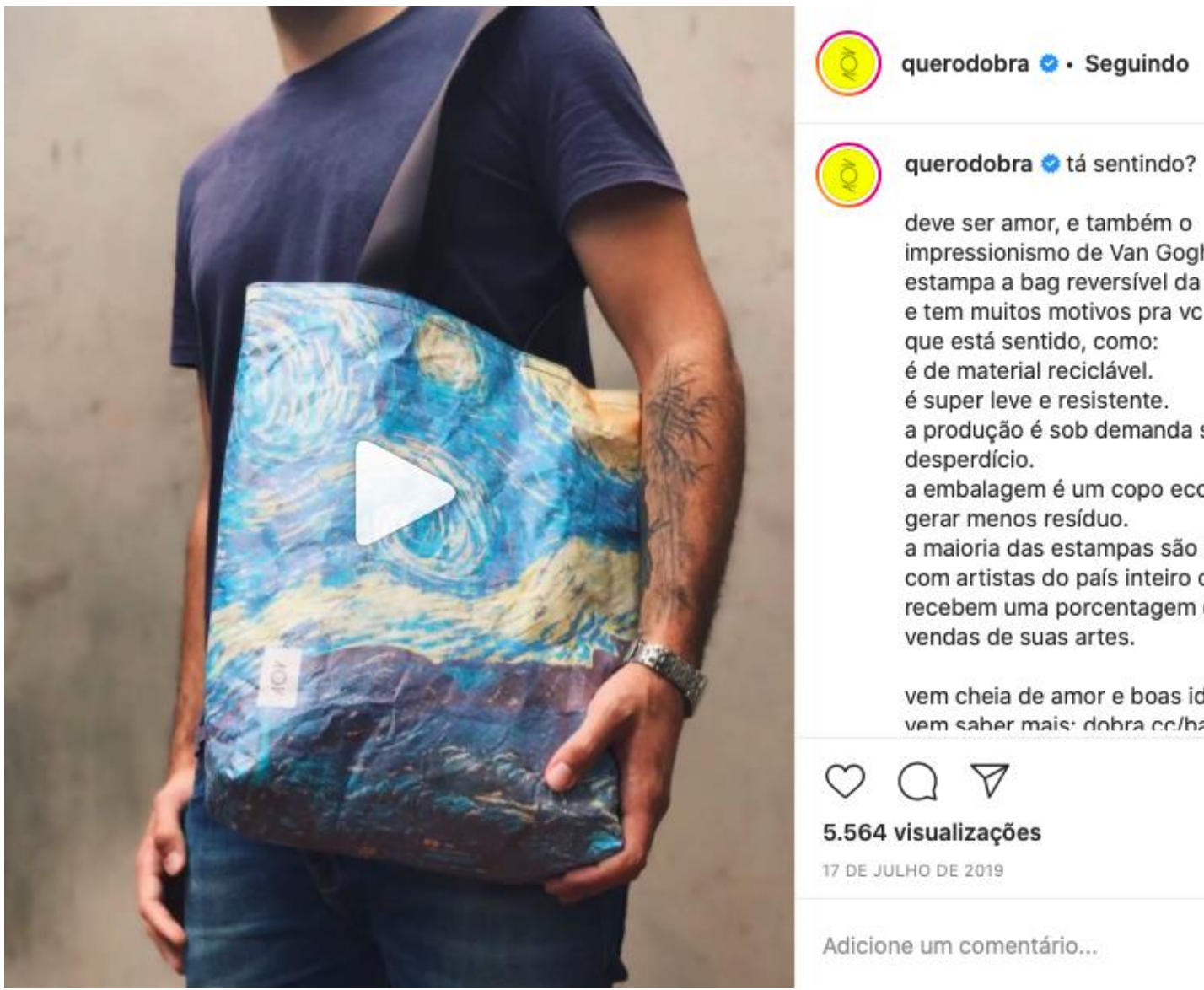
impressionismo de Van Gogh que estampa a bag reversível da dobra. e tem muitos motivos pra vc sentir o que está sentido, como: é de material reciclável. é super leve e resistente. a produção é sob demanda sem desperdício.

a embalagem é um copo eco, pra gerar menos resíduo. a maioria das estampas são collabs com artistas do país inteiro que recebem uma porcentagem das vendas de suas artes.

vem cheia de amor e boas ideias vem caher maic' dnhra re/han

Figura 5. Postagem falando sobre o design da bolsa.

Fonte: Instagram @Querodobra

Dentro dos discursos de sustentabilidade, as embalagens tornaram-se uma espécie de vilã no mundo da moda, criticadas pelo excesso de recursos utilizados, descartados quase que imediatamente após a compra. No caso da Dobra, a embalagem se torna em si um item a reforçar a postura ecológica da empresa, já que esta é um copo, que serve para que o consumidor não apenas deixe de desperdiçar a embalagem do produto comprado, mas passe também a economizar o uso de copos plásticos, no consumo cotidiano de água. Como revela o post abaixo, o copo, através de sua associação com o seu conteúdo líquido, serve ainda para falar da qualidade do produto: "resistente e não tem problema de molhar". O texto explica ainda como a bolsa chega ao consumidor, brincando com ideia de que aquilo que antes era visto como um problema pelo consumidor convencional (chegar amassada), torna-se um charme adicional do produto e da marca. Nesse aspecto, a ético e o design ajudam a minimizar a insatisfação de receber um produto que chega amassado, fazendo com que o consumidor dê novos significados a forma amassada e já espere isso ao fazer o seu pedido. 


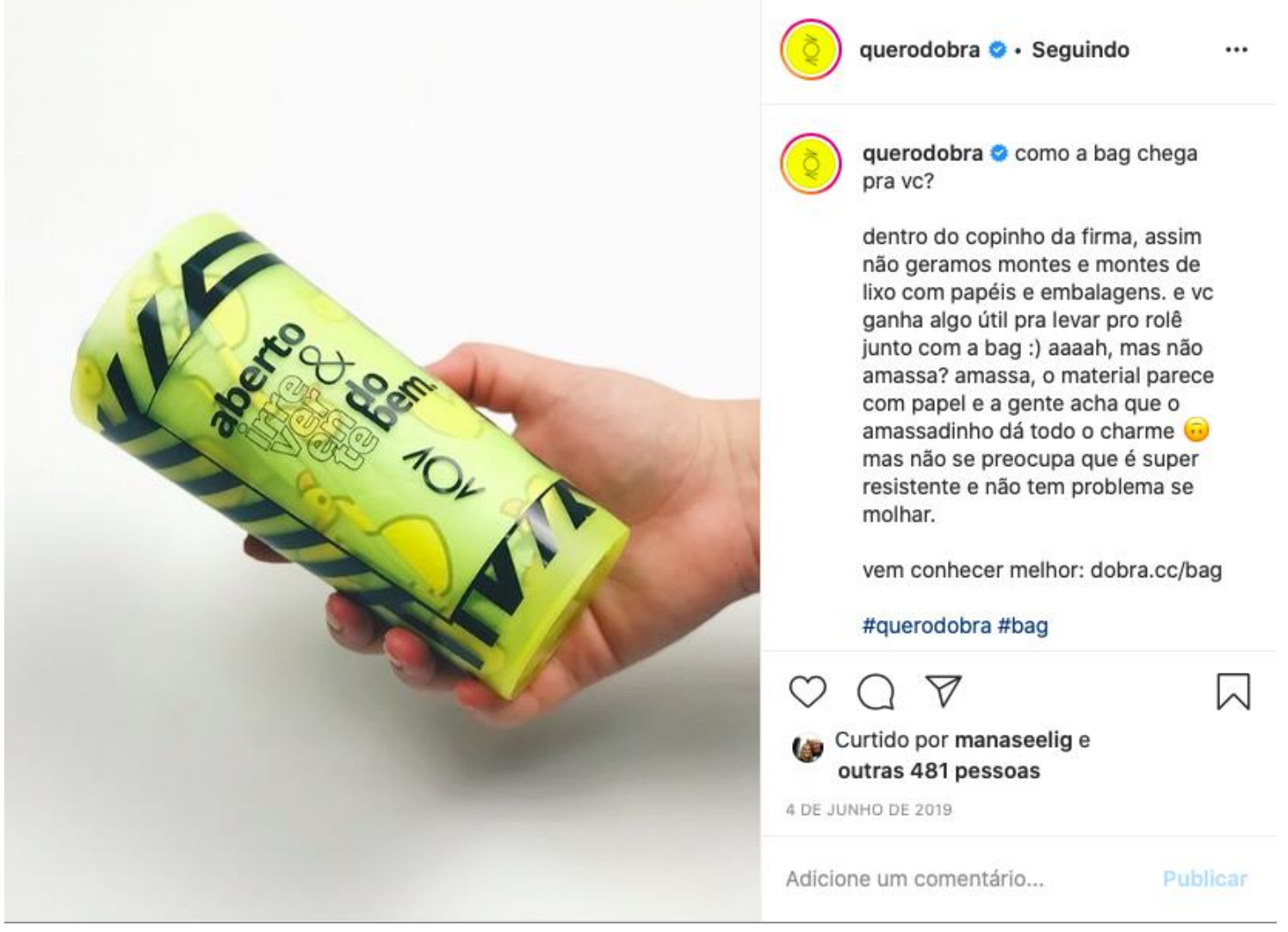

Figura 6. Postagem sobre o copo eco.

Fonte: Instagram @Querodobra

\subsection{Comunicação e co-criação}

Na comunicação da marca, observou-se o esforço de consolidar uma comunidade ao seu redor. A marca busca ter com os seus consumidores uma relação que extrapola o ato da compra; visando criar narrativas de amizade e proximidade. De forma a concretizar esse processo de aproximação, a marca aplica o que eles chamam de "metodologia de conversa de bar". Tal abordagem não é algo capcioso ou subliminar, mas ao contrário, explicitado pela marca nos materiais e manuais de gestão e de transparência de marca, disponibilizados no seu site. $\mathrm{Na}$ "metodologia de conversa de bar" a linguagem utilizada é a corrente nas redes sociais, sem formalidades e com uma descentralização dos meios de comunicação que o consumidor tem com a marca. Assim, estes podem interagir com a Dobra seja por mensagem direta no perfil, pelos comentários ou até mesmo pelo site e e-mail. Com isso, a Dobra constrói uma rede que dá a sensação de que todos estão sentados em um grande sofá numa sala, e dentro desta sala não há diferença hierárquica entre consumidores e marca - o que cria um campo que possibilita a Dobra manter conversas com seus consumidores que não necessariamente permeiam a publicidade de um produto. A comunicação da marca segue o fluxo da comunicação que acontece entre amigos nas redes, ou ainda, algo mais próximo da interação realizada entre seguidores e influenciadores digitais, que tem um caráter pessoal e desenvolvem uma maior intimidade com seu público. A Figura 7 apresenta um post que sintetiza os recursos que a empresa se utiliza para conversar com os consumidores. 


\section{SEVCPUDESSE \\ VOLTARNO TEMPO, OQUEVCDIRIA PRAVCMESMO?}

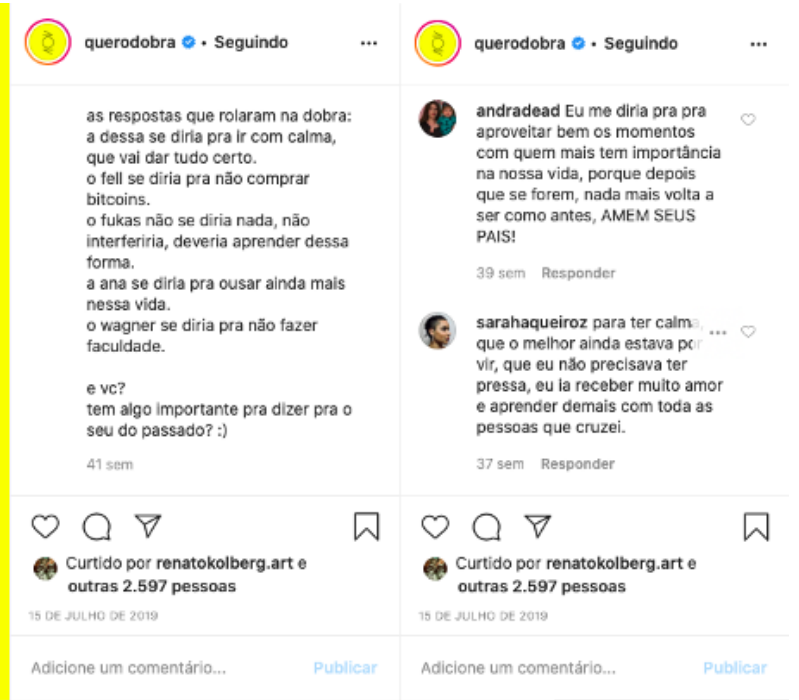

Figura 7. Exemplo de postagem que visa somente dialogar com os consumidores

Fonte: Instagram @Querodobra

O post acima não busca promover um produto ou falar de qualquer iniciativa comercial da Dobra. A postagem sugere uma conversa, fazendo a pergunta sobre as histórias e aprendizados dos consumidores. Para esquentar essa interação, o texto apresenta algumas respostas dadas pelos funcionários da dobra: "pra ir com calma", "não comprar bitcoins", "ousar mais nessa vida", "não fazer faculdade". Essas falas transmitem alguns dos valores que a marca sustenta na sua comunicação - um estilo de vida menos acelerado e calcado nos aspectos financeiros, a partir de uma postura ousada e pouco convencional. O chamado para conversa é aceito pelos consumidores da Dobra que curtem e compartilham suas próprias histórias, numa dinâmica clara de co-criação do conteúdo. No lugar de ser a única voz e personagem no centro da interação, a Dobra abre espaço para que os consumidores aprendam uns com os outros, e descubram valor na experiência dos demais internautas.

No lado do consumidor, este campo que a Dobra utiliza para transcender o status de marca para como se fosse uma entidade - num processo de quase personificação; se mostra como um espaço de co-criação; onde com base nas interações consumidor-marca e feedbacks de produtos - são consolidados novos produtos, conteúdos e serviços co-criados. Neste caso, é importante ressaltar este processo de co-criar se mostrou relacionado a um certo grau de intimidade do consumidor, onde este por livre vontade faz uma sugestão, como foi o caso da bolsa da figura 5, um exemplo de desenvolvimento de novos produtos.

O consumidor sugere que a Dobra inicie uma nova categoria, além de bolsas, produzindo pochetes. Mais do que receber sugestões, no contexto da plataforma digital a marca pode também obter um termômetro da aceitação da audiência, observando como o produto é recebido pelos demais consumidores. A marca usualmente não rejeita as sugestões, deixando isso para os demais consumidores. A Dobra, ao contrário, reforça essa abertura para receber os comentários, sempre respondendo e sinalizando como ela agrega esses inputs ao desenvolvimento de novas coleções e tipos de produtos. 
O posicionamento ativo e co-criador dos consumidores vai além das sugestões de design. Em diversos posts, os consumidores também se apresentam como promotores espontâneos da marca, gerando conteúdo no Instagram. Essa integração que ocorre graças à redução da barreira consumidor-marca; com o sentimento de pertencimento, conforme foi observado no comportamento dos clientes da Dobra, gera também como efeito uma amplificação no marketing de produto. Através de clientes embaixadores, como exemplificado no post abaixo, a marca ganha energia na internet. $O$ consumidor em questão relata a surpresa ao receber os produtos sonhados, junto com um recado escrito à mão. Tais depoimentos acabam não apenas por atrair mais consumidores, mas também incentivar uma base de consumidores engajados, que postam suas experiências com o produto.
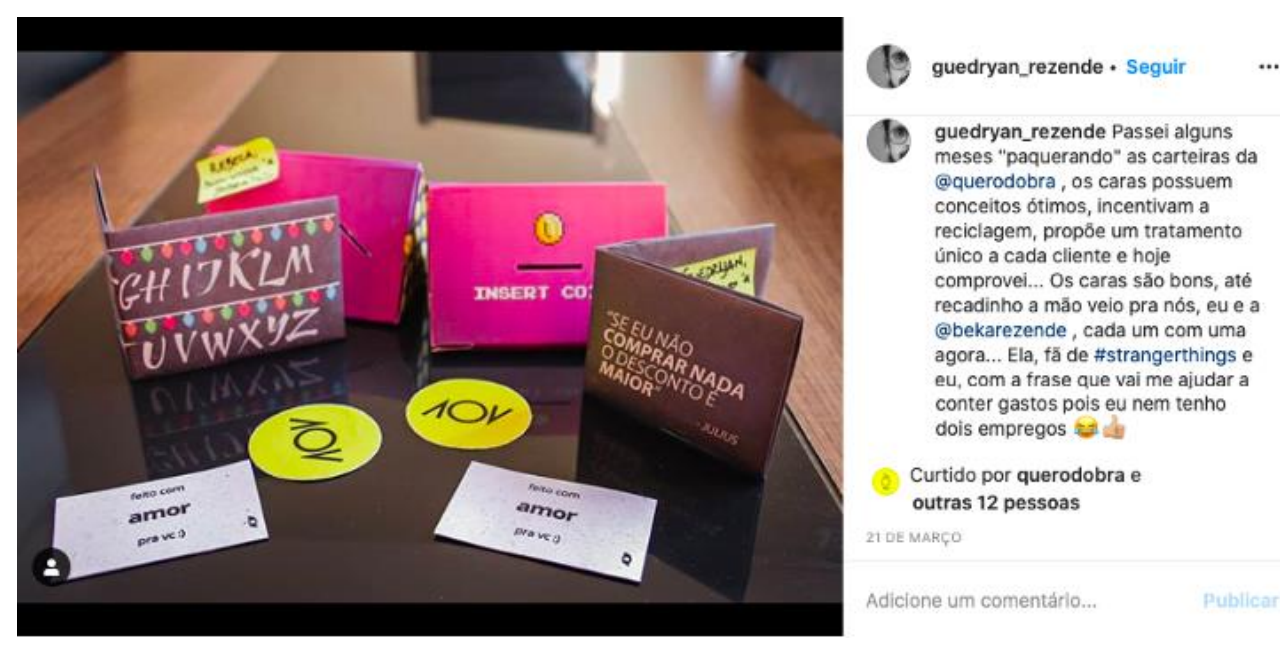

Figura 8. Exemplo de um consumidor-embaixador da marca

Fonte: Instagram @Guedryan_rezende

\subsection{O processo circular de slow fashion}

A análise dos posts e da comunicação da Dobra se alinha a estudos anteriores, destacando a importância da comunicação no processo de implementação do slow fashion. No seu framework original, Pookulangara e Shephard (2013) destacam a ênfase na educação e a importância de se constituir o foco no investimento e longevidade nesse processo (Figura 9). 


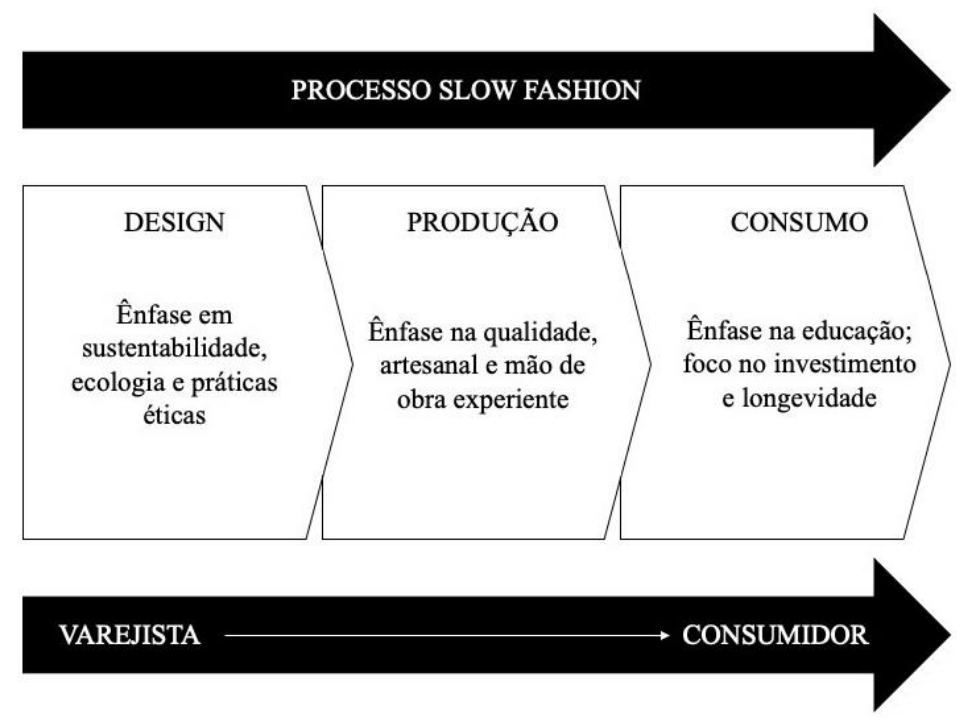

Figura 9. Processo Slow Fashion.

Fonte: Pookulangara e Shephard (2013, p. 202).

A partir da análise do caso da Dobra, foi possível perceber, contudo, que a representação linear do processo slow fashion não contempla os efeitos e a importância da co-criação nesse contexto. Na apresentação de forma linear, o processo slow fashion é representando a partir de um caráter unidirecional, onde a empresa conduz essa dinâmica, desenvolvendo, produzindo e educando o consumidor. A partir da nossa análise, alertamos para o fato de que nesse processo são fundamentais as dinâmicas de co-criação, em fluxos multidirecionais de comunicação. Como destacamos a partir dos posts analisados, os consumidores tem um papel ativo, no sentido de apresentar sugestões de novos produtos, construir conteúdo sobre a marca e educar os pares. Nesse sentido, os consumidores são uma peça importante na legitimação da lógica slow fashion e o valor da marca nesse contexto. A constituição de narrativas que se originam não apenas dentro da empresa, mas no ecossistema em torno dela, contribui para tornar o consumidor mais consciente das suas escolhas - agregando valor à marca coletivamente.

Entender o processo de slow fashion como um fluxo unidirecional parece representar as premissas da indústria tradicional da moda, que coloca os compradores da marca como demanda/mercado, ou seja, receptores das tendências e criações ditadas pela indústria. Tal framework não contempla a possibilidade de um consumidor ativo, que faz parte do processo de criação da oferta e da marca. O framework original de Pookulangara e Shephard (2013) também deixa de contemplar a energia que a interação com os consumidores agrega ao processo de design e produção da marca. A partir do caso Dobra, o presente artigo sugere o aperfeiçoamento do modelo original em duas direções: 1) incluindo a co-criação com os consumidores, como elemento importante no processo de educação, valorização da lógica slow fashion e design 2) evidenciando a natureza circular (e não linear) do processo slow fashion. 


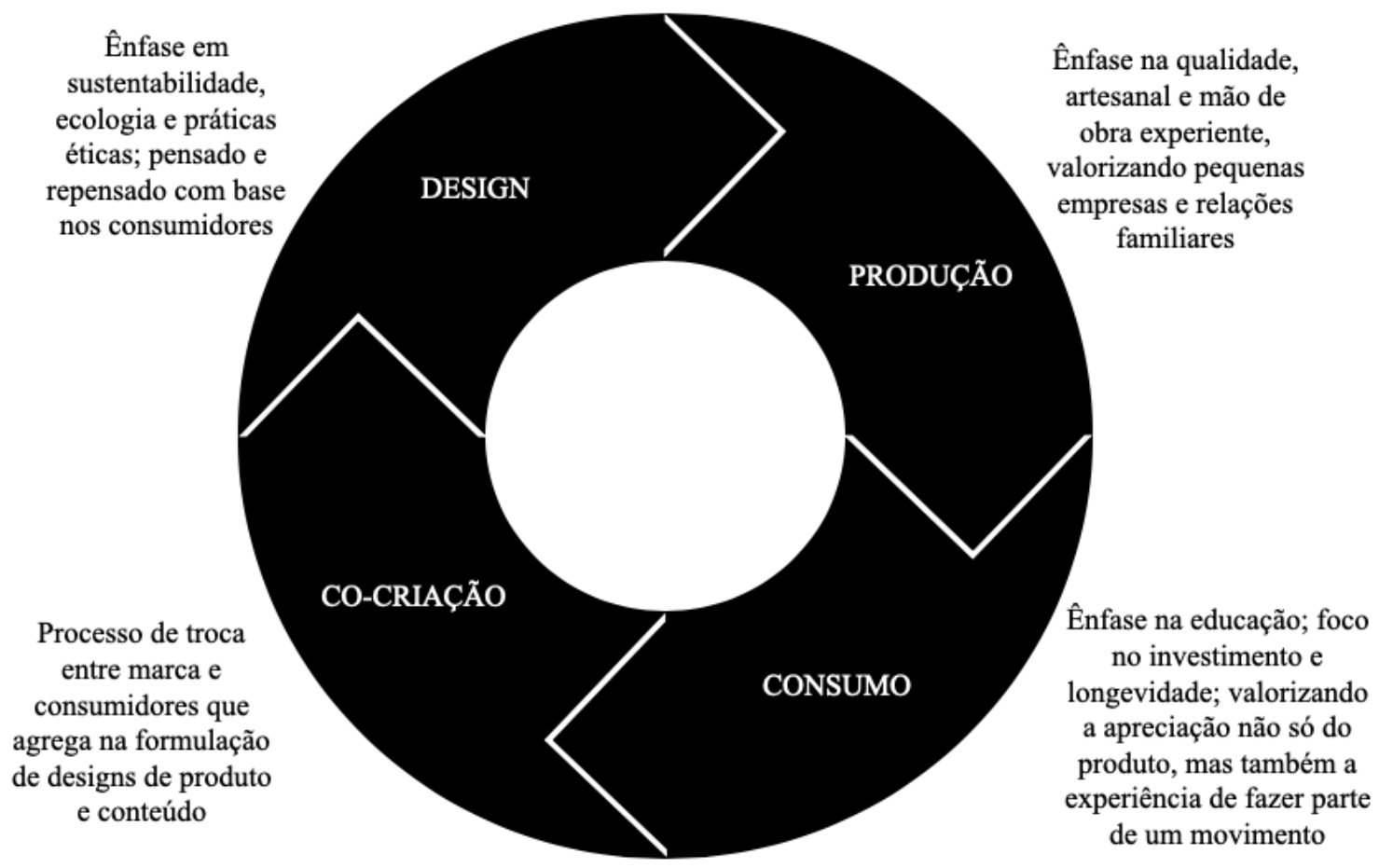

Figura 10. Processo circular de Slow Fashion.

Fonte: Elaborado pelos autores

A ênfase circular do processo acaba por ter um caráter diferenciado por agregar as reações e feedbacks, de volta ao início do processo de design e produção. A figura considera ainda dinâmicas de influência mútua, entre pares, de um consumidor que se preocupa com quem produziu o que ele consome (POOKULANGARA; SHEPHARD, 2013). Essa ideia de circularidade parece ser fundamental no contexto de sustentabilidade. Além disso, o framework aponta para as possibilidades criadas pelas dinâmicas comerciais da internet. Ao comprar uma peça em um shopping center por exemplo, o comprador dificilmente tem a possibilidade de contato direto com a marca, os designers e desenvolvedores do produto. Quanto maior for essa marca, menor a possibilidade dessa interação direta se concretizar. Contudo, quando se trata do meio digital - que tem se mostrado cada vez mais importante no contexto da moda, surgem diversas interações que não são previstas em processos mais tradicionais como a abordagem utilizada por Pookulangara e Shephard (2013).

Ao enxergar o processo slow fashion como um fluxo circular constante sendo reiniciado pela co-criação, considera-se a importância da participação do consumidor no processo criativo da marca. Como efeito, tem-se a possibilidade de gerar um produto, conteúdo ou até mesmo algum novo serviço, agregando mais valor nesta segunda fase do ciclo ao que é oferecido pela marca, consolidando, assim, um processo circular de slow fashion.

A circularidade, por fim, fortalece o processo de inovação da marca, pois insere diretamente no seu processo de inovação um alto grau de diversidade e multiplicidade que transcende o corpo efetivo de funcionários da marca. Abrindo espaço para a co-criação, a empresa amplia assim as fontes de inovação, acessando valores e visões de mundo externos 
à empresa. Tal abertura se concretiza nos produtos que o consumidor deseja e acredita gerando no consumidor um sentimento de pertencimento; onde ele extrapola a condição de cliente e passa a integrar a marca.

\section{Considerações Finais}

A aplicação da co-criação dentro da perspectiva do slow fashion mostrou trazer resultados bastante relevantes para a evolução do movimento - acelerando e diversificando o processo de reflexão da própria empresa - que culmina na inovação. A forma circular de se entender a relação entre consumidor e marca nesta nova perspectiva de consumo contempla de forma mais direta uma nova geração de consumidores que deixam de conhecer marcas por terem lojas em shoppings ou então anúncios em revistas de moda. Estes têm a possibilidade de conhecer novas marcas principalmente pelas redes sociais, interagir e trocar com o ecossistema em torno da marca, que inclui os funcionários, os fornecedores e outros consumidores da marca. Com isso, é possível afirmar a relevância da comunicação das marcas com o seu público em mídias sociais; visto que a publicidade tradicional se mostra menos eficiente nestes espaços virtuais em comparação a marcas que desenvolvem uma comunicação capaz de gerar consumidores engajados. Se o intuito do slow fashion é desacelerar o consumo por meio de um processo educativo com o consumidor; nada melhor que um diálogo claro, limpo e direto - onde o consumidor deixa de ser entendido como passivo no processo para uma parte ativa; capaz de colaborar e co-criar com as marcas o próprio processo educativo.

O trabalho analisou as interações entre a Dobra e seus consumidores no ambiente virtual. Estudos futuros podem investigar como a interação com uma marca slow fashion e as interações educativas em torno desse modelo modifica outros padrões de consumo. Seria o consumidor desacelerado da moda mais propenso a adotar essa dinâmica no consumo de outras categorias como, por exemplo, alimentação e turismo? Pesquisas futuras podem mapear o processo de formação e transformação de consumidores para o movimento slow fashion. A Dobra se apresenta como uma empresa jovem e de pequeno porte dentro do ecossistema da moda. Outra questão interessante de pesquisa em torno do slow fashion diz respeito a como grandes empresas e marcas consolidadas se apropriam dessa lógica e como as dinâmicas de co-criação se modificam em função da natureza da marca. Estariam os consumidores dispostos a desenvolver "conversas de bar" com grandes corporações, como fazem com a Dobra? Para estudos futuros, há espaços ainda para se investigar outras marcas do varejo tradicional, com lojas físicas, avaliando as narrativas em torno dos encontros entre vendedores e compradores, no ambiente físico das lojas. Como se viabiliza a lógica slow fashion nesse contexto? Como o ecossistema e as narrativas se transformam? Por fim, o presente estudo inventariou as narrativas presentes na plataforma do Instagram. Outras mídias sociais como Youtube, Pinterest, Facebook e Twitter se apresentam como plataformas e ferramentas cotidianas de rearticulação de dinâmicas de consumo e desaceleração. Estudos futuros nesses espaços podem nos ajudar a entender as narrativas slow fashion de forma mais ampla.

\section{Referências Bibliográficas}

CONWAY, D.; TIMMS, B. F. Re-branding alternative tourism in the Caribbean: The case for 'slow tourism'. Tourism and Hospitality Research, v. 10, n. 4, p. 329-344, 2010. 
ÉPOCA NEGÓCIOS. Slow fashion: Como se adaptar ao movimento que preza pela moda sustentável.

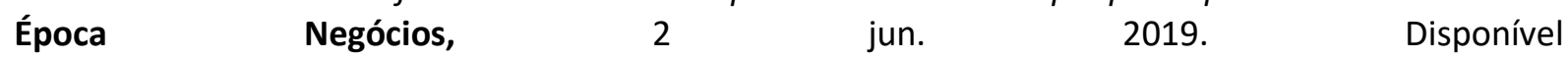
em: <https://epocanegocios.globo.com/Mercado/noticia/2019/06/pegn-slow-fashion-como-seadaptar-ao-movimento-que-preza-pela-moda-sustentavel.html>. Acesso em: 25 maio 2020 FLETCHER, K. Slow fashion: An invitation for systems change. Fashion Practice, v. 2, n. 2, p. 259-265, 2010.

FLETCHER, K. Durability, fashion, sustainability: The processes and practices of use. Fashion practice, v. 4, n. 2, p. 221-238, 2012.

JUNG, S.; JIN, B. A theoretical investigation of slow fashion: Sustainable future of the apparel industry. International Journal of Consumer Studies, v. 38, n. 5, p. 510-519, 2014

HUMPHERY, K. The time of consumption. In: OSBALDISTON, N. (Ed.). Culture of the slow: Social deceleration in an accelerated world. Nova York: Springer, 2013. p. 19-23.

HUSEMANN, K. C.; ECKHARDT, G. M. Consumer deceleration. Journal of Consumer Research, v. 45, n. 6, p. 1142-1163, 2018.

KOZINETS, R. V. (2015). Netnography: Redefined. Thousand Oaks: SAGE.

MACKEY, J.; SISODIA, R. (2013). Capitalismo Consciente: Como libertar o espírito heroico dos negócios. São Paulo: HSM Editora.

MIRANDA, A. P.; MONÇORES, A. Esse tal de Espírito do Tempo... Revista Dobras, v. 6, n. 14, p. 53-59, 2013.

OH, H.; ASSAF, A. G.; BALOGLU, S. Motivations and goals of slow tourism. Journal of Travel Research, v. 55, n. 2, p. 205-219, 2014.

OSBALDISTON, N. (2013). Culture of the slow: Social deceleration in an accelerated world. Nova York: Springer.

OZDAMAR ERTEKIN, Z.; ATIK, D. Sustainable markets: Motivating factors barriers, and remedies for mobilization of slow fashion. Journal of Macromarketing, v. 35, n. 1, p. 53-69, 2015.

PARKINS, W.; CRAIG, G. Slow living and the temporalities of sustainable consumption. In POTTER, E.; LEWIS, T. (Eds.). Ethical Consumption: A Critical Introduction. Reino Unido: Routledge, 2011. p. 189200.

POOKULANGARA, S.; SHEPHARD, A. Slow fashion movement: Understanding consumer perceptionsAn exploratory study. Journal of retailing and consumer services, v. 20, n. 2, p. 200-206, 2013.

SASSATELLI, R.; DAVOLIO, F. Consumption, pleasure and politics. Journal of Consumer Culture, v. 10, n. 2, p. 202-232, 2010.

SCHOR, J. From fast fashion to connected consumption: slowing down the spending treadmill. In: OSBALDISTON, N. (Ed.), Culture of the slow: Social deceleration in an accelerated world. Nova York: Springer, 2013. p. 34-51.

THOMPSON, C. J. Interpreting consumers: A hermeneutical framework for deriving marketing insights from the texts of consumers' consumption stories. Journal of Marketing Research, v. 34, n. 4, p. 438, 1997.

VITORIO, T. (2019, novembro 28). Esta empresa fatura cerca de $R \$ 2,5$ mi por ano e tem um cachorro como CEO. Exame, 28 nov. 2019. Disponível em: <https://exame.com/pme/esta-empresa-fatura-r-25mi-por-ano-e-tem-um-cachorro-como-ceo/>. Acesso em: 25 maio 2020.

ZARLEY WATSON, M.; YAN, R. An exploratory study of the decision processes of fast versus slow fashion consumers. Journal of Fashion Marketing and Management, v. 17, n. 2, pp. 141-159, 2013. 